\title{
IMPOSSIBILIDADE DE ALTERAÇĀO DE LEI COMPLEMENTAR POR LEI \\ ORDINÁRIA EM MATÉRIA TRIBUTÁRIA
}

Marcelo de Lime Castro Diniz"

SUMARIO: 1. Introduça. 2. A Natureza Juridica da Let Complementar 3 Diferencas ente lei complementar e le ordinaria. 4. Os aspectos material formal da Lei Complementar. Principios da seguranca juridica e da proteça da confiança. 5. A experiencia da Constituicăo portuguesa. As leis reforcadas e a questao do quotum. 6. Competencias implicitas competencias explicitas. poder discricionario do legisladon 7. Concusoes. 8. Biblografa.

SUMMARX: 1. Introduction. 2. The jurdic nature of complementary. 3. Differences through complementary low and ordinary law 4. The material aspects and form of complementary law Principles of juridic security and protection of confidence. 5. The experience of Portuguese constitution. The reinforement law and the quortm's question. 6. Implicit competences and explicit competences. Descricimary power of legislator 7. Conclusion. 8 . Bublography.

UBERSICHT: 1. Einführng. 2. Die Rechtsnatu des Erganzungsgesetzes. 3. Unterschicde zwischen dem Erganzungsgesetz and dem gowhulichen Ceselz. 4. Materielle Gesichtspunkte und Fom des Erganzungsgesetzes. Die Prinzipien der Rechssicherheit und des Vertrauensohutzes. 5. Die Effohnngen der

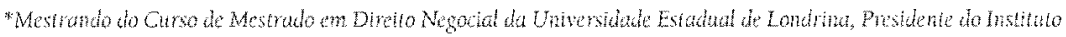

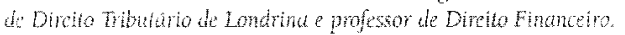


portugiesischen Verfassing. Die Gesetzesbekräfgung und die Frage des Qitorums. 6. Stillschweigende und ausdrühliche Zuständigket. Gestalnangstreheit des Gesetzgebers. 7. Schlussfolgerungen. 8. Biblographie.

RESUMO: É comum que o legislador regule um determinado assunto por meto de lei complementar, embora pudesse fazê-lo através de lei ordinaria, cujo processo legislativo é diferente, sobretudo pela questao do quorum. Una lei com essas caracteristicas deve ser considerada lei complementar, decorrendo dai que sua modificaça apenas ê possivel por noma do mesmo escalão, em face dos princípios da mais valia legitimatoria e da liberdade de conformaçao do legislador na atividade legislativa.

ABSTRACT: Usually the legislator controls a specific subject through a complementary law, al though it can be done through a ordinary law which is diferent concerning the legislative process, matnly on the quorum matter. A law with these characteristics must be considered complementary law, so that its modification is only possible by a norm on the same level. According to the principles of "more value legitimatory" and liberty of conformation of the legislator in his legislative activity.

ZUSAMMENFASSUNG: Es ist üblich, dass der Gesetzgeber cine bestimmte Materie durch Erganzungsgesetz reget, obwoht er dies auch durch gewönliches Gesetz könte, bei dem das Gesetzgebungsverjohren anders ist, insbesondere wegen der Frage des Quorums. En derartiges Gesetz muss als Ergänzungsgesetz angesehen werden; daraus ergibt sich, dass seine Abönderung nur durch eine Norn derselben Sufe moglich ist, da her die Grundsätze der "gesetzgeberischen Hoherrangigkeit" und der "Anpassungsfreihett" des Gesetzgebers bei seiner Gesetzgebungstatigheit gelten.

PALAVRAS-CHAVE: Constituçâo. Lei complementar Lei ordinaria hierarquia. Competência. Quorum. Mais valia legitimatoria. Liberdade de conformaçäo.

KEY-WORDS: Constitution. Complementary law Ordinary law. 
Hierarchy, Liability, "Quorum", "More value legitimatory". Liberty of conformation.

SCHLÜSSELWÖRTER: Das Integration entsprincht. Das argentinische Gesetz nr. 24.822. Das innerstaatliche Recht. Zucker. Rechtspreching.

\section{Introdução}

O presente estudo destina-se a analisar a viabilidade constitucional de modificação de norma inserta em lei complementar por lei ordinária. Assim ocorreu com a Lei Complementar n. 70/91, que foi alterada pela Lei n. 9.7].8/98 (lei ordinária)'.

A Lei n. $9.718 / 98$ alterou a Lei Complementar 71/90, promovendo algumas modificaçöes na sistemática de cobrança da COFINS, tais como a elevação da alíquota para $3 \%$ e o alargamento da base de cálculo (de faturamento para receita).

Destaca-se que a Lei Complementar n. 70/91 é materialmente lei ordinária, pois o art. 195 da Constituição não exige norma qualificada para a instituiçăo da contribuiçăo social sobre o faturamento.

Com efeito, existem duas correntes muito bem definidas sobre o tema em estudo. De um lado, há aqueles que prestigiam o aspecto material em detrimento do aspecto formal. Dizem os primeiros, que, se a matéria predicada na Constituição é da competência da lei ordinária, a lei complementar que preencher esse espaço, como tal nảo poderá ser considerada, mas sim como mera lei ordinária, suscetível, pois, de alteraçảo por norma do mesmo escalão2.

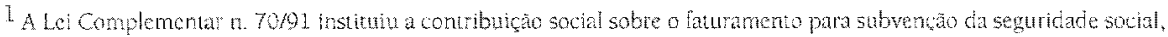

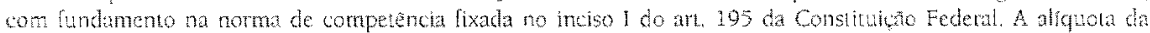

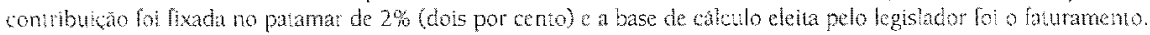

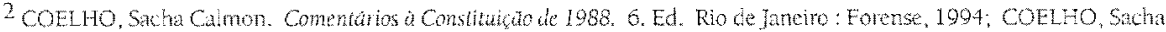

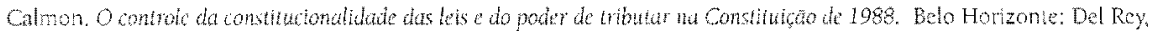

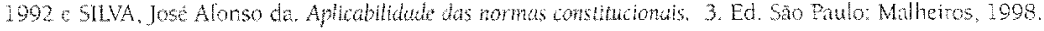


Não obstante, sustenta a outra corrente que a Constituição também reconhece ou diferencia as normas pelo seu aspecto lormal. Argumentam que uma lei näo pode ser qualificada, simultaneamente, como lei ordinária e complementar, bem como que o legislador possui uma certa margem de liberdade - discricionariedade - na eleição da espécie normativa que regulara um determinado tema predicado na Constituição, observada a ordem hierárquica. Assim, é possivel a conciliação dos aspectos formal e material em matéria legislativa, sobretudo porque a Constituição não estabelece hierarquia entre os mesmos.

\section{A natureza juridica da lei complementar}

Muito se debate sobre a natureza juridica da lei complementar, desde que esta categoria normativa foi introduzida no ordenamento jurídico brasileiro.

Victor Nunes Leal, antes das Constituições de 1967 e 1988, averbou que nada diferenciava uma lei complementar de uma lei ordinária. Ressalvava, contudo, que a lei complementar regula temas sensiveis, sendo uma longa manus da Constituiçäo+.

Após a promulgaçăo da atual ordem constitucional, a situaçáo tomou-se bem diferente. Tem-se diferenças marcantes entre a lei complementar e a lei ordinária.

Sacha Calmon Navarro Coelho leciona que as leis complementares, inclusive as tributarias, säo entes legislativos reconhectveis formal e materialmente (forma e fundo). Quanto ao aspecto formal - prossegue o mestre mineiro --, o que diferencia a lei complementar é a questão do quorum, enquanto que, sob o aspecto material, a diferenciação reside no fato de que as leis

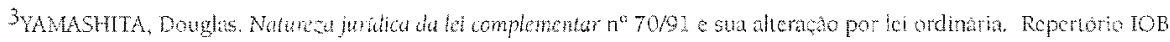
de Jurispudencia Sao Bulo. n. 7., p. 227-231, 1. quinzena de abm de 1909 .

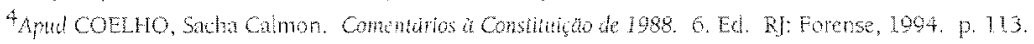


complementares têm por principal missăo complementar os comandos constitucionais $^{5}$.

José Afonso da Silva ensina que ...as leis complementares adquiriram superioridade formal relativamente as outras leis, num status intermédio entre leis constitucionais e leis ordinarias...., esclarecendo ainda que As leis constitucionais modificam a Constituição, integrando-se nela. Constituem normas constitucionais em sentido formal, por onde já se nota que têm a mesma hierarquia das demais disposiçóes da Constiuição e, portanto, gozam de superioridade em relação às leis complementares...

Desta forma, não se pode dizer que a Constituição não valorizou o aspecto formal em matéria legislativa. Se toda matéria inserta na Constituição tem tal status, independentemente de não se tratar de norma materialmente constitucional, é certo que o elemento formal foi decisivo para se chegar a tal conclusão. Em suma, pouco importa se o tema não devia estar na Constituição; se está, é norma constitucional.

Ao estudar os princípios da competencia e da hierarquia, Canotilho apregoa que, ao contrário de se confundirem ou se contradizerem, um principio completa o outro. Para o jurista lusitano, o principio hierárquico acentua o caracter de limite negativo dos actos normativos superiores em relação aos actos normativos inferiores, ao passo que o principio da competência pressupóe antes uma delimilação positiva, incluindo-se na competencia de certas entidades a regulamentação material de certas matérias (ex.: pertence às regioes autonomas legislar sobre as materias de interesse especifico da regiāo)

Deve-se ressaltar que, efetivamente, existe uma relaçăo de hierarquia e subordinação entre as normas jurídicas, estando no ápice a norma constitucional. Convivem os aspectos material e formal neste ambiente de hierarquia das normas.

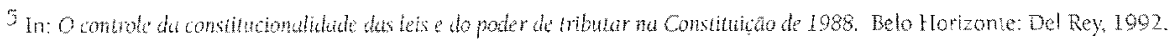
P. 285

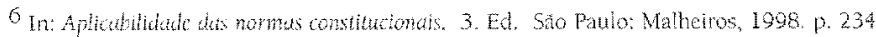

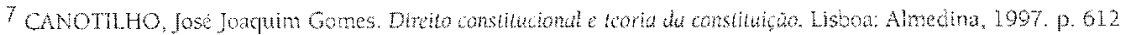


O aspecto formal traduz segurança, na medida em que, estando uma noma inserta em uma lei complementar ou mesmo na Constituição, tem-se a segurança de que apenas uma outra norma de igual ou superior hierarquia é que poderá modificá-la; ấ reside o cerne do princípio da hierarquia, quando Canotilho qualifica-o como limite negativo.

O valor segurança também está presente, quando se sabe que uma norma, quanto mais alta estiver no escalão hierárquico, mais dificil será sua alteração em face da previsão de quoruns especiais, trazendo proteção e segurança quanto aos aspectos da estabilidade da lei e, das relações juridicas.

Para Hans Kelsen, todas as normas do sistema estão sujeitas a uma norma fundamental, que constitui a fonte primária do poder. As demais nomas - sempre dependentes da norma fundamental - não se encontram em uma relação de coordenação, mas sim de ordenaçáo normativa ou inseridas em uma estrutura escalonadas.

Se, para Kelsen, competencia consiste em uma autorizaçio para produzir normas juridicas, resta evidente que, se a ordem jurídica não proibe, - legislador está autorizado a produzir uma determinada norma juridica de escalão superior, na medida em que una norma juridica näo vale porque tem um determinado conteudo, quer dizer, porque o seu conteudo pode ser deduzido pela via de um raciocínio lógico do de uma norma fundamental pressuposta, mas porque é criada por uma forma determinada - em útlima análise, por uma forma fixada por uma noma fundamental pressuposta.

Desta lorma, não se pode sobrepor o aspecto material ao aspecto formal em matéria legislativa, visto que o ordenamento jurídico nāo alberga essa conclusăo. Não há, pois, hierarquia quanto às questóes de forma e de conteúdo.

\section{Diferenças entre lei ordinária e lei complementar}

Perscrutando-se a Constituição em vigor, verifica-se que existem diferenças entre a lei ordinária e a lei complementar, tanto sob o prisma material, quanto sob o prisma formal.

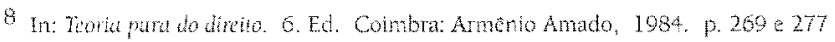

9 KELSEN, op, cil., p. 273
} 
Com eleito, no plano constitucional, não se discute se uma noma $e$ materialmente inconstitucional, pois o que importa é estar inserida na Constituicão; prevalece, assim, o elemento formal.

Por outro lado, também näo se desconhece que existem campos de atuagăo para a lei complementax e para a lei ordinária, devidamente delimitados pela Constituicăo, ressaltando-se, pois, o elemento material.

O elemento fomal mostra-se fundamental em relaçăo ao quorum para aprovação, bem como em vista do respectivo processo de aprovação É pelo aspecto formal que a norma se apresenta no ordenamento jurídico.

Douglas Yamashita realça diferenças entre as duas leis, afirmando que, além da questão pertinente ao quorum, o artigo 61 da Constituiça Federal de 1988 distingue claramente a iniciativa de le complementar da iniciativa de lé ordinaria ${ }^{10}$

Nessa ordem de idéias, é licito concluir-se que um projeto de lei ordinaria aprovado por maionia absoluta não se torna lei complementar apenas porque foi observado o quorum necessário à aprovação desta espécie nomativa. Um projeto de lei ordinária apenas pode dar origem a uma lei ordinária, ocorrendo o mesmo em relaça a um projeto de lei complementar.

Hugo de Brito Machado, por sua vez, leciona que ...em sistemas juridicos como o nosso, as nomas ganham identidade e se posicionam no escalonamento hierárquico em razâo de seus aspectos formais, a saber, em razão do órgăo que a produz e do procedimento adotado em sua producāon.

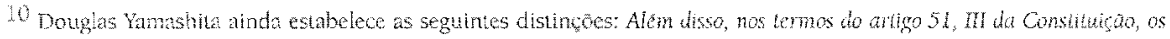

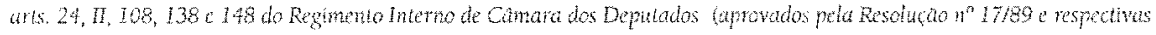

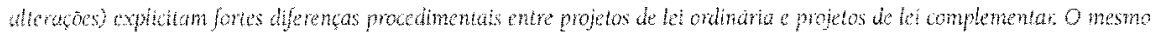

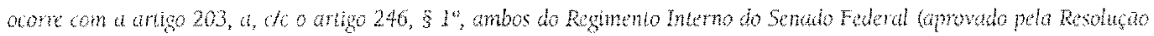

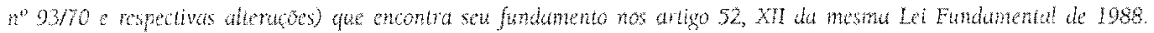
(YMASHITA, op. cit., p. 230)

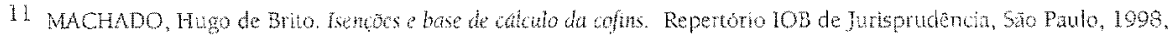
a. 23. p. 609-61. 1. quinzera de dezembro de 1998 .
} 
Alfredo Augusto Becker entende que os critérios de forma e de conteudo na interpretação das leis năo possui qualquer valor cientifico' ${ }^{2}$. Entende o jurista gaúcho que, no plano normativo, não há distinçăo entre as questóes de forma e de conteudo, não sendo lícito concluir-se que um aspecto se sobreponha ao outro.

E assim conclui seu raciocinio: É um erro tradicional na hermenêutica juridica a dicotomia entre forma e conteudo de lei. A forma e o conteudo da regra jurtica - na verdade - surgem simultaneamente. Surgem do mesmo e unico esforço intelectual que faz a forma e o contendo surgirem do caos e da indoléncia ${ }^{13}$.

Sacha Calmon Navarro Coelho entende que, em matéria legislativa, quem pode o mais pode o menos. Vale dizer, se o legislador pode editar lei ordinária em lace da competência que the foi outorgada pela Constituiçăo, também pode fazêtlo por meio de lei complementar ou emenda constitucional, ou seja, por meio de ato legislativo superior no escalonamento hierárquico. Contudo, adverte com relaçào à lei complementar: Se regular matéria de competéncia da Uniào reservada à lei ordinaria, ao invés de inconstiucionalidade, incorre em queda de status, pois terá valência de simples lei ordinaria federal't.

Se, de fato, o aspecto mais importante para a Constituição em matéria legislativa losse o material, com certeza teria que ser reconhecida a inconstitucionalidade da lei complementar que invadisse o campo de atuação privativo da lé ordinária. A própria assertiva quem pode o mais, pode o menos traduz uma predisposição para a existência de hierarquia entre as normas, na medida em que, em sentido oposto, quem pode o menos, näo pode o mais.

Em sintese, se quem pode o mais, pode o menos, e se quem pode o menos, não pode o mais em matéria legislativa, está mais do que reafirmado o princípio da hierarquia das leis, o que também denota a não prevalência do aspecto material em matéria legislativa.

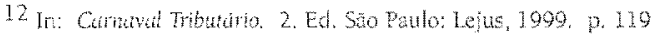

13 BECRER, of CH. p. 119

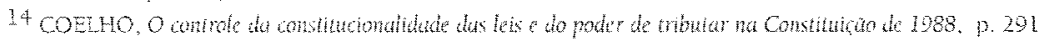




\section{Os aspectos material e formal da lei complementar. Princípios da segurança jurídica e da proteção da confiança}

Se foi observado o devido processo legislativo para criação de lei definida pelo legislador como complementar, então se trata de lei complementar e como tal deve ser tratada, sob todos os aspectos.

A norma se faz conhecida e reconhecida pela sua objetividade, pela forma como se apresenta no ordenamento juridico. Se a norma apresenta-se como lei complementar, observado o devido processo de sua aprovaçăo, assim deve ser considerada.

Neste ponto, observa-se que a questão do quorum é de suma importância para a definiçăo da natureza jurídica de uma norma, além das respectivas regras procedimentais para aprovaçăo. Dizer que a questăo do quorum é questão de somenos importância importa em agressão à própria noção de poder.

Com eleito, existe uma intima relação entre a questão do quorum com a origem do poder. A Carta Magna apregoa que todo o poder emana do powo (parágrafo único do artigo $1^{\circ}$ ), tendo sido escolhido o sistema representativo, através do qual a soberania popular será exercida pelo sufragio universal e pelo voto direto e secreto (Constituiçăo Federal, artigo 14).

Desta forma, o poder, que pertence ao povo, é manifestado ostensivamente através dos seus representantes, que compöem as Casas Legislativas. É evidente que quando a Constituição reclama um quorum qualificado, como é o caso da aprovação de uma lei complementar, o que realmente está em jogo é a manifestação do povo, que deve ser mais contundente em alguns casos do que em outros. Amesquinhar a grandeza do quorum em matéria legislativa importa em agressão ao próprio princípio que afirma estar no povo a origem de todo o poder.

A edição de uma lei complementar traz mais segurança aos cidadãos, na medida em que o quorum para aprovação é mais elevado. O quorum 
qualificado postula dos parlamentares uma maior discussão na aprovação do respectivo texto legal. A dificuldade para alteração é vista como importante instrumento de estabilidade das relações jurídicas.

O princípio da segurança jurídica é ínsito à noção de Estado Democrático de Direito (Constituição Federal, artigo $1^{\circ}$.) . O próprio preâmbulo da Constituição eleva a segurança a nível de princípio fundamental, o mesmo ocorrendo com o artigo $5^{\circ}$., caput, da Constituição Federal.

Canotilho ensina que o princípio da segurança jurídica está intimamente ligado às necessidades do homem: O homem necessita de segurança para conduzir, planificar e conformar autónoma e responsavelmente a sua vida. Por isso, desde cedo se consideravam os principios da segurança juridica. e da proteção da confiança como elementos constitutivos do Estado de direito ${ }^{15}$.

Deste modo, se o princípio da segurança jurídica compagina-se com as necessidades do homem (povo), e considerando-se que todo o poder emana do povo (homem) e em seu nome será exercido, crê-se que a questão formal ou de quorum na aprovação de uma lei complementar é manifestamente relevante. Repita-se: desprezar este aspecto ou supervalorizar o aspecto material em seu prejuizo importa em agressão frontal ao texto constitucional, em todas as suas bases e fundamentos.

\section{A experiência da Constituição Porguesa. As leis reforçadas e a questão do quorum.}

Dentro do contexto da Constituição Portuguesa, também existem várias categorias de leis. Dentro da categoria das leis reforçadas, existem as leis orgânicas; as que postulam a aprovação por maioria de dois terços; as que por força da Constituição sejam pressuposto normativo necessário de outras leis; e as leis que por outras devam ser respeitadas ${ }^{16}$.

15 CANOTILHO, op. cit., p. 250

16 CANotillo, op. cit., p. 684-689 
Na óptica de Canotilho, quanto às leis que exigem a aprovação por maioria de dois terços sobressai o aspecto formal, tendo sido consagrado o critério da 'mais valia legitimatória', ou seja, o critério da maioria reforçada exigido para a sua aprovacao ${ }^{37}$.

Percebe-se que a Constituição Portuguesa, assim como ocorre com a nossa Constituicão, prestigia o elemento formal, bem assim o aspecto do quorum para aprovação das suas leis. Vè-se, pois, que a questão do quorum é de suma importância para a caracterizaçăo de uma lei reforçada, que se diz reforçata justamente pelo critério da mais valia legitimatória.

No Brasil, embora não haja leis reforçadas, tem-se as leis complementares, que também se sobressaem pelos aspectos formal e do quorum qualificado para aprovaçăo.

Seria violentar tanto a Constituição portuguesa, como a Constituição brasileira, a alteração de uma lei aqui complementar e lá reforçada por uma lei sem esse traço formal ou que não reclame maioria qualificada para aprovaçao; seria amesquinhar o critério da mais valia legitimatória, que se lez presente para a edição da lei, mas não para sua alteração, o que importa em direta agressäo ao próprio Estado de Direito.

Canotilho adverte que algumas leis säo reforçadas porque reforçada é a maioria requerida para a sua aprovaçá (maioria de dois terços). Nesse sentido, verifica-se que a exigência de quorum reforçado para a aprovação de leis reforcadas tem o sentido de expressar que a maioria reforçada constitucionalmente exigida revela o relevo politico-constitucional destas leis tal como acontece em relaçăo às leis orgânicas ${ }^{18}$.

Aqui, como lá, é de suma importância a questão formal e de quorum para aprovação de uma lei. Como ressaltado por Canotilho, uma lei reforçada (ou complementar) realça a importância político-constitucional da matéria por ela regulamentada, cujo juízo crítico de ordem politicoconstitucional näo pertence ao jurista, mas sim ao legislador, a quem

17 CANOTLLO, op. th, p. 684-689

18 CNNOTILO, op cit, p. 684-689 
compete cumprir a Constituicäo, tornando eficazes e efetivos seus principios e objecivos.

\section{Competencias implicitas e competências explícitas. Poder discricionario do legislador}

A Constitucăo Federal alberga dois tipos de competencia, as explicitas e as implicitas.

As competencias implicitas são aquelas não individualizadas ou mencionadas no texto constituciond, mas que se podem ainda considerat como implicitamente derivadas das nomas constucionais eschitas ${ }^{19}$

Assim, posstrel compatibilizar-se a teoria propugnada por Sacha Calmon ce que, em matéria legislativa, quem pode o mats pode o menos, com a teoria das competencias implicitas adotada por Canotilho.

Imagine-se uma situacáo em que um tema pudesse ser regulado por lei ordinaria ou, como querem alguns juristas, fosse da competencia da lei ordinatia, mas o legislador houvesse por bem a erigi-lo a nivel constitucional, mediante emenda à Constituicão. Houve, evidentemente, invasăo da competencia da lei ordinäria, mas ninguém ousaria alimar que a natureza da emenda constitucional neste caso seria de lei ordinaria $e^{2}$ por oura lei ordinária pudesse ser alterada.

Acredita-se estar implicito na Constituição a prerrogativa (competencia) de o legislador adotar uma noma superior herarquicamente - mas jamais interior - ao invés daquela espécie normativa expressamente consagrada no texto constilucional. O próprio texto do artigo 61 , caput, da Constituicazo, sinaliza neste sentido, ao apregoar que A iniciativa das leis complementares e ordinarias cabe a qualquer..

E por que o legislador faria isto? Justamente para prestigia os valores seguranca e protecăo da confiança, que, como visto, foram expressamente

19 CANOTLHO, op, ell., p. $492-493$ 
exaltados pelo Texto Constitucional. A utilização desta competência implícita mostra-se adequada quando necessária à consecução dos fins do Estado, na forma concebida pela Constituição.

A doutrina norte-americana também vê a possibilidade da existência de competencias implicitas no seio da Constituição. Tratam-se dos chamados poderes implicitos (implied powers): poderes näo expressamente mencionados na Constituiçăo, mas adequados à prossecuçäo dos fins e tarefas constitucionalmente atributdos aos orgäos de soberania ${ }^{20}$.

Ao contrário de Douglas Yamashita ${ }^{21}$, não se entende que a Constituiçäo outorgue algum poder discricionário ao legislador. A atividade legislativa é plenamente vinculada à Constituição. Aceitamos, contudo, a possibilidade de a Constituição outorgar uma certa liberdade de conformação na produção do ato legislativo.

Como Carta Política que é, a Constituiçăo consagra valores e principios devidamente moldados pelo legislador ao produzir as normas jurídicas, mediante uma conformaçăo livre dos fins politico-sociais enunciados na Constituição. Isto näo significa discricionariedade, na concepção que a doutrina do direito administrativo apregoa: oportunidade e conveniência. Antes, denota o caráter vinculado da atividade legiferante a Constituição.

Qualquer valoração, escolha ou ponderação do legistador deve guardar estrita observância ao que enuncia a Constituição. Ao produzir o ato legislativo, dispõe o legislador de uma certa margem de liberdade, de forma a adequar a norma aos principios e valores consagrados na Constituiçăo; porém, tal prerrogativa não significa oportunidade e conveniência (discricionariedade).

Se o legislador - atento ao princípio da segurança jurídica - houve por bem regular uma matéria através de norma superior na hierarquia em relação àquela especificamente prevista pela regra de competência, é porque valeu-

20 CANOTHHO, op, cil. p. 493

21 WAMASHTTA, op, di. p. 227-231. 
se da liberdade de conformação ínsita na Constituição, para cumprir os comandos constitucionais mais importantes: seus princípios ${ }^{22}$.

Nessa mesma linha de raciocínio, Douglas Yamashita assevera que: Restringir o uso de leis complementares apenas às matérias expressamente discriminadas pela Constituição, como quer a doutrina tradicional, significaria desprezar a inestimável segurança juridica que tais diplomas legais podem proporcionar. Certamente, não é esse o espírito da Carta Constitucional de $1988^{23}$.

Como bem frisou o Ministro Marco Aurélio, em direito, o meio justifica o fim, mas não este àquele ${ }^{24}$. No mesmo sentido, Canotilho observa que a abertura de alternativas no esquema meios-fins é, porém, indiscutível, no plano legislativo ${ }^{25}$.

Para a consecução dos interesses tutelados pela Constituição, é certo que o legislador está autorizado a concretizá-los com certa liberdade de conformação. No entanto, encontra-se plenamente vinculado a exercer sua competência dentro dos estritos parâmetros fixados pela Constituição, quanto aos fins, interesses, valores, princípios e forma lá consagrados.

Por todos esses aspectos, pode-se concluir que nas situações em que a Constituição não exige lei complementar para regular determinada matéria, esta facultado o uso dessa espécie normativa, em vista da liberdade de conformação consagrada pela Constituição.

Nesta ordem de idéias, quando o legislador houve por bem disciplinar a COFINS por meio de lei complementar, valeu-se de prerrogativas

22 A propósito, atente-se para a seguinte liçāo de CANOTILHO: No ämbilo das nomas consitucionats estruluralmente aproximadas de "clausulas gerais", o legistador dispoe de um amplo domfnio politico para ponderar, valorar e comparar os fins dos preceitos consitucionais, proceder a escolhas e tomar decisóes. Esta actividade de "ponderaçuo", de "valoraçäo" e de "escolha" implica que o legislador, embora juridico-consitucionalmente vinculado, desenvolve una actividade politica oriundu. năo subsumivel a esquenas de "execucóes" ou "uplicaça" de leis consilucionais. A politica, nesta perspectiva, deveria ser uma "politica constilucionat", mas nūo se reduziria a "realizaço" de normas consitucionais. Seria, sim, uma conformacüo live dos Jins politico-sociais enunciatos na consituiçuo. (In: Constituição dirigente e vinculaçào do legislador. Coimbra: Coimbra, 1994. p. 21B)

23 VAMASHITA, op. cil., p. 229

24 BRASHL. Supremo Tribunal Federal. Acordão. Recurso Extraordinário n. 166.772-RS. Relator Ministro Marco Aurelio.

25 CANOTLLHO, Direito constitucional, e Teoria da Constituição, p. 684-689 
implícitas no sistema jurídico-constitucional. Deste modo, tratar uma lei complementar como ordinária, na medida em que regula matéria sob competencia desta última, representa uma atitude depreciativa à autoridade do Poder Legislativo e à soberania popular plasmada objetivamente na norma juridica (Constituição Federal, art. $1^{\circ}, \S 1^{\circ}$ ).

\section{Conclusões}

Em face das considerações expendidas, conclui-se:

- A lei complementar apresenta-se como tal não só pelo seu aspecto material, mas também pelo seu aspecto formal;

- No plano da hierarquia das leis, a lei complementar situa-se em patamar superior à lei ordinária;

- As normas junidicas situam-se no escalonamento hierárquico em razão dos seus ascpectos formais;

- Os primados da segurança juridica e da proteção da confiança informam o legislador na elaboração de leis complementares;

- A lei complementar traz mais segurança aos cidadãos, na medida em que o quorum para sua aprovação é mais elevado, dificultando, pois, sua alteraça, decorrendo daí uma maior estabilidade da norma, como também das respectivas relaçoes juridicas:

- Há relação direta entre a origem do poder (povo) e a exigencia de quorum qualificado para aprovação de certas classes de atos legislativos;

- O critério da mais valia legitimatoria (Canotilho), que se fez presente para a aprovação de uma lei com determinado status, também deve estar presente para sua modificação;

- Não existe poder discricionário do legislador. O que a Constituição The outorga é uma liberdade de conformação, permitindo-lhe, pois, uma conformação livre dos fins politico-sociais enunciados na Constitução (Canotilho); e 
- Dentro desta esfera de liberdade de conformação se o legislador elege um determinado tema para ser regulado por uma norma de hierarquia superior, importa em direta violação ao texto constitucional qualquer modificaça introduzida nessa norma por lei de hierarquia inferior.

\section{BIBLIOGRAFIA}

BARROSO, Luis Roberto. Interpretaço e aplicacan da constituçäo. Săo Paulo: Saraiva, 1996 BECKER, Alfedo Augusto. Torin geral do dreto tributario. 3. Ed. Sao Paulo: Lejus, 1998. BECKER, Alfedo Augusto. Cantaral Tribuario. 2. Ed. Säo Paulo: Lejus, 1999.

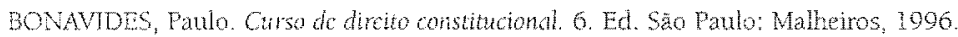
CANOTLHO, Jose Jaquim Gomes. Constituicano drigente e vinculaça do legisiador: Combra: Coimbra, 1994.

CANOTLHO, Jose Joaquim Gomes. Diwito Constiucional e Tenta da Constiulç̄o. Lisboa: Almedina, 1997

COELHO, Sacha Calmon Navarro. Comentänos à constituiçăo de 1988. 6. Ed. Rio de Janeiro; Forense, 1994.

CoEltro, Sacha Calmon Navaro, O controle dia constitucionalidade das leis a do poder de tributar na consiluticho do 1988. Belo Horizonte: Del Rey, 1992.

FERRERA FUHO, Manoel Gongalves Curso de Direio Constimciondi. 17. Ed. São Panlo: Sarava, 1989. KELSEN, Hans. Ton a pura do dreito. $6^{2}$ ed. Combra: Amento Amado, 1984

NEVES, Luis Fernando de Souza Cofms-contributço sndal sobre foturtmento. Să Paulo: Max Limonad, 1997.

SIVA Jose Atonso da Aplicabildade das nomas constincionais. 3. Ed. Sä Paulo: Malheiros, 1998. Artigos Doutrinários:

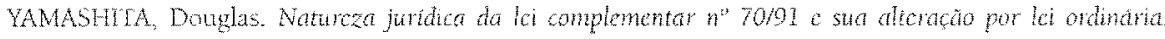
Repertório $10 \mathrm{~B}$ de Jurisprudéncia Sāo Pálo. n. 7, p. 227-231, l. quinzena de abril de 1999.

MACHADO, Hugo de Bito. Isenços $c$ base de calculo da cofins. Repertorio IOB de Jurispudencia, Sso Paulo, 1998, n. 23, p. 609-61.1, 1. quinzena de dezembro de 1998.

Decises Judicis

BRASIL. Supreno Tribunal Federal. Acórdăo. Recurso Extraordinário n. 166.772-R5. Relator Ministro Marco Aurtio. 